\title{
Persistence in Political Participation
}

\author{
Marc Meredith*
}

\footnotetext{
*Assistant Professor, University of Pennsylvania, Department of Political Science, 208 S. $37^{\text {th }}$ Street, Philadelphia, PA 19104-6215. E-mail: marcmere@upenn.edu

I am grateful to Dan Kessler for his guidance on this project. I also thank the QJPS editors and referees for substantially improving this paper. Finally, I thank Jon Bendor, Doug Bernheim, Alan Gerber, Jason Grissom, Casey Klofstad, Keith Krehbiel, Anna Mastri, Paul Oyer, Connor Raso, Doug Rivers, Ken Shotts, Erik Snowberg, Jonathan Wand, Christian Wheeler, and audiences at the University of Chicago Harris School, Emory University, Georgetown University, Harvard University, University of Pennsylvania, Princeton University, University of Wisconsin, Yale University, and the 2006 Midwest Political Science Association Conference for their helpful comments and suggestions.
} 


\begin{abstract}
This paper uses discontinuities imposed by voting-age restrictions to identify the effect of past eligibility on subsequent participation decisions and partisan identification. It compares participation decisions and partisan affiliations of individuals who turned eighteen just before past elections with those who turned eighteen just after. It presents three main findings. First, past presidential election eligibility increases the probability of subsequent participation. For example, my point estimates indicate that 2000 presidential election eligibility increased participation in the 2004 presidential election by 3.0 to 4.5 percent, which suggests that voting in the 2000 presidential election increased 2004 participation by about 5 percentage points. Second, past presidential election eligibility affects partisan identification. Third, these effects continue to persist for several election cycles after a voter first becomes eligible.
\end{abstract}


Researchers in political socialization debate the importance of adolescences' and young adults' political experiences for shaping future political behavior. Early political experiences are hypothesized to affect later turnout (Butler and Stokes 1969; Campbell, Converse, Miller, and Stokes 1960; Miller 1992; Miller and Shanks 1996; Plutzer 2002), partisan affiliation (Jennings and Markus 1984; Markus 1979; Sears and Valentino 1997), and polarization (Mullainathan and Washington 2006). This work suggests that inertial forces cause initial political behaviors to persist in the long-run. Some of this research particularly emphasizes the importance of individuals' first voting experiences (Campbell et. al 1960; Franklin 2004; Franklin, Lyons, and March 2004; Mullainathan and Washington 2006; Plutzer 2002).

Yet, despite the importance of this issue, few papers convincingly identify the causal effects of early participation. Individuals choose whether to participate in elections, making it difficult to separate the effects of early voting experiences from the forces that caused individuals to participate in the first place. Because individuals' unobserved taste for voting or a political party are likely to be positively related across time, standard least-squares estimates of the effects of past on current turnout are likely to overstate its true causal effect (Green and Shachar 2000). For this reason the magnitude and even the existence of an effect of early participation decisions on subsequent political behavior is largely an open question.

This paper solves the above identification problem by using a regression discontinuity approach. Voting-age restrictions provide an exogenous source of variation in the first voting experiences of young voters by dividing similarly aged citizens into cohorts of individuals eligible and ineligible to participate in a given election. The $26^{\text {th }}$ 
Amendment of the U.S. Constitution guarantees citizens over the age of eighteen the right to vote. As a result, people born on November 7, 1982 were eligible to vote in the 2000 presidential election between George W. Bush and Al Gore, while people born on November 8, 1982 were not be able to cast a vote for president until they were nearly twenty-two. Absent voting restrictions, no theoretical reasons exist to expect systematic differences in the political behavior of the cohorts of individuals born immediately before and after November 7, 1982. Any significant differences in the subsequent political behavior of the two cohorts can thus be attributed to differences in the experiences of the cohorts resulting from eligibility in the year 2000 .

I first estimate how 2000 presidential election and 2002 midterm election eligibility affects participation in the 2004 presidential election. I then discuss how to use these estimates to approximate the effect 2000 on 2004 participation. I also investigate whether 2000 or 2002 eligibility affects the probability of affiliation with political parties. Next, I examine how 2000, 2002, 2004, and 2005 election eligibility affects turnout in the 2006 midterm election. Finally, I test whether eligibility in other presidential and midterm elections prior to 2000 continues to affect 2004 participation and partisan affiliation.

\section{Literature}

Since the publication of The American Voter, political scientists have recognized the importance of early political experiences in shaping political behavior (Butler and Stokes 1969; Campbell, Converse, Miller, and Stokes 1960; Franklin 2004; Franklin, Lyons, and March 2004; Hyman 1959; Jennings and Markus 1984; Markus 1979; Miller 
1992; Miller and Shanks 1996; Mullainathan and Washington 2009; Plutzer 2002; Sears and Valentino 1997). Some of this work emphasizes how first voting experiences can have long-lasting effects of political orientations (Campbell et. al 1960; Franklin 2004; Franklin, Lyons, and March 2004; Plutzer 2002). More recently, several papers document the positive correlation between past and current decisions in the most central political behavior: voter turnout (Brody and Sniderman 1977; Goldstein and Ridout 2002; Verba and Nie 1972). As a result, Plutzer (2002, p. 42) argues that "virtually all major works on turnout have concluded that voting behavior is, in part, a gradually acquired habit."

Scholars use the existence of persistence in political participation to explain broader political phenomena such as macro trends in voter turnout. Assuming voting is habitual and that the probability of abstention decreases with age, Franklin and Franklin, Lyons, and March (2004) argue that citizens are more likely to become habitual nonvoters if they are first eligible to vote at age eighteen rather than twenty-one. An additional implication of this theory is that in the long-run individuals who are first eligible to vote at eighteen should be less likely to vote than individuals who are first eligible to vote at twenty-two.

Behavioral voting models also use assumptions about persistence in political participation to explain why substantial turnout occurs despite Downs' paradox of voting. Bendor, Diermeier, and Ting (2003) and Fowler (2006) assume that individual's decisions of whether to participate in the next election are affected by the outcome of the previous election. Specifically, individuals who vote for winning candidates derive

\footnotetext{
${ }^{1}$ Because persistence in political participation may occur for non-psychological reasons (see Achen (2006) for an example), the term state dependence better reflects the phenomenon than habit.
} 
psychological benefits, while individuals who vote for losing candidates face psychological costs, which are applied towards their voting calculus in the subsequent election. This suggests that past participation may have differential effects depending on individuals' partisan persuasions.

Despite the obvious importance of accurate estimates of the causal effect of past on current participation to these theories, little previous work has isolated the effect of past participation from individual differences in preferences. As discussed above, leastsquares estimates of the effect of past participation on current participation confound the true causal effect with unobserved differences in voters' preferences. To isolate the causal effect, an instrument that affects past turnout decisions but is independent of individuals' subsequent unobserved taste for voting is needed. ${ }^{2}$

Gerber, Green, and Shachar (2003) use a random experiment in which voters were targeted by a get-out-the-vote (GOTV) drive in New Haven, Connecticut to identify persistence in turnout. The authors chose a random group of registered voters in New Haven to receive mailings or personal contacts prior to the 1998 midterm election. They compare these voters' participation to voters who received no contact. They find significantly higher turnout in both the 1998 midterm and the subsequent 1999 local election among registered voters treated with either a mailing or personal contact. Their point estimates suggest that voting in the 1998 midterm election increased the probability of participating in the 1999 local election by about 50 percentage points.

\footnotetext{
${ }^{2}$ Green and Shachar (2000) and Denny and Doyle (2009) use instruments from national panel surveys to overcome the identification problem. For example, Denny and Doyle assume that the number of locations of residence between the ages of 16 and 23 is negatively related to turnout when young, but unrelated to turnout in subsequent elections. These papers find a significant relationship between past and current turnout using their IV specifications. These results hinge on the validity of assumptions about non-random instruments. The number of locations of residence between 16 and 23, for example, is likely to be related to schooling decisions, which in turn affect the likelihood of participation (Dee 2004).
} 
Although Gerber, Green, and Shachar (2003) provide evidence of persistence in political participation, their method has some significant limitations. First, Gerber, Green, and Shachar use a one-time experiment whose findings may not necessarily generalize to the larger electoral environment. Voters in New Haven, Connecticut may not be representative of the typical American voter and the effects of past participation may vary across different electoral environments (i.e. weakly contested local election versus contested presidential election). Second, while the effects of GOTV drives on subsequent voting behavior could be tested across a variety of electorates and electoral environments, it may be difficult and costly to administer and standardize. Third, using GOTV to test for persistence requires tracking voters and their treatment status across time. Because individuals who move across voting jurisdictions (typically counties or townships) are dropped from subsequent voting records, it is difficult to make inferences about persistence over longer time horizons. Finally, the local average treatment effect (LATE) property of instrumental variables estimation implies that Gerber, Green, and Shachar's estimate of persistence applies to the small subpopulation of individuals that are induced to vote by GOTV targeting (Imbens and Angrist 1994). As I discuss in the conclusion, there are reasons to suspect that the LATE on this subpopulation may be substantially different than on the voting population at-large.

I use voting-age restrictions rather than a GOTV experiment as my source of exogenous variation in past participation to identify persistence. There are several comparative advantages. First, voters across all voting jurisdictions and elections in the United States face a common voting-age restriction. Hence, unlike with GOTV targeting, it is easy to compare the effects of voting-age restrictions across electorates and electoral 
environments. In addition, knowledge of a citizen's birth date is sufficient to determine treatment status, thereby eliminating the need to track voters over time and enabling the study of persistence over a much longer time horizon. Finally, voting-age restrictions estimate a LATE for a broader subpopulation than GOTV targeting.

Mullainathan and Washington's (2009) study of the effects of past participation on attitudinal variables also uses voting-age restrictions as an instrument. They find that two years following a presidential election, 20 and 21 year olds (eligible to vote in the previous presidential election) have more polarized political opinions than 18 and 19 year olds (ineligible to vote in previous presidential election). While our papers are complementary, my paper offers some significant advantages. Mullainathan and Washington compare differences in survey respondents' evaluations of presidents and congressional representatives. In contrast, I focus on differences in actual behavior. In addition, by using a large dataset from a homogenous political environment, I am able to estimate the effect of past participation much more precisely around the voting-age discontinuity than Mullainathan and Washington.

\section{Data and Methods}

My empirical tests compare the behavior of individuals who are as similar as possible, with the sole exception of their eligibility or ineligibility to vote in a prior election. Participation and partisan identification data are taken from the California Statewide Voter File (CSVF), which contains information on residential location, partisan identification, voting history, and exact date of birth for all registered voters in the state 
of California. ${ }^{3}$ The CSVF provides an extremely large sample; 65,412 registered voters with birthdates between September 21, 1982 and December 20, 1982 are listed in the CSVF.

Ideally, I would be able to use the CSVF data to estimate Equations 1 and 2, where $Y_{i, 1}$ and $Y_{i, 2}$ are indicators for whether individual $i$ voted in time periods 1 and 2, $Z_{i}$ is an indictor for whether individual $i$ was eligible to vote in time period $1, X_{i, t}$ is a matrix of covariates for individual $i$ in time period $t$, and $\varepsilon_{i, t}$ is the unobserved determinants of turnout for individual $i$ in time period $t$. In this framework $\theta$ represents the percentage point change in the probability of participating in time period 2 resulting from participation in time period 1 . Because $\varepsilon_{i, 1}$ and $\varepsilon_{i, 2}$ are believed to be nonindependent, $E\left[\varepsilon_{i, 2} \mid Y_{i, 1}\right] \neq 0$, and therefore Equation 2 can not be estimated unbiasedly using ordinary least squares (OLS). However, if $Z_{i} \perp \varepsilon_{i, 2}$, I can estimate Equation 2 by instrumental variables (IV).

(1) $Y_{i, 1}=\alpha_{1}+\beta_{1} X_{i, 1}+\delta Z_{i}+\varepsilon_{i, 1}$

(2) $Y_{i, 2}=\alpha_{2}+\beta_{2} X_{i, 2}+\theta Y_{i, 1}+\varepsilon_{i, 2}$

Unfortunately, two features of the CSVF prevent me from being able to directly estimate Equations 1 and 2. First, I only observe registered voters. Because past election eligibility may affect both registration and turnout decisions, restricting the sample to only registered voters could bias the results. Second, voting history from time period 1 is only observed for individuals who have remained in the same county between time

\footnotetext{
${ }^{3}$ Other common sources of participation data (CPS, ANES) lack information either on date of birth or a large enough sample to make inferences.
} 
periods 1 and 2. As a result, the CSVF substantially underestimates the proportion of the eligible population that participated at the initial election.

Given these limitations of the CSVF, my empirical strategy is to analyze the behavior of cohorts of individuals who are divided with respect to past election eligibility. I use the CSVF to aggregate the number of voters participating in the 2004 California presidential election and the 2006 California midterm election by date of birth. I then use data on births from Natality Detail files, which give information on the number of births in California by date, to deflate these turnout counts. ${ }^{4}$ A daily turnout ratio is constructed by dividing the number of participants in the CSVF by the number of California births in the Natality Detail files. I investigate whether there are effects of past election eligibility on logged daily turnout ratios, which can be interpreted as the intentto-treat effect of past participation on subsequent participation in percent terms. ${ }^{5}$

Once I estimate the effect of eligibility on turnout ratios, I attempt to back out the effect of past on current participation under the IV exclusion restriction that $Z_{i} \perp \varepsilon_{i, 2}$. In practice this is similar to replacing $Y_{i, 1}$ with the fitted value $\hat{Y}_{i, 1}$ obtained from estimating Equation 1 and then estimating Equation 3:

(3) $Y_{i, 2}=\alpha_{2}+\beta_{2} X_{i, 2}+\theta \hat{Y}_{i, 1}+\varepsilon_{i, 2}$.

\footnotetext{
${ }^{4}$ Because a random sample of only 50 percent of the total births in California are recorded from 19691984, I double the birth counts for these years when constructing the turnout ratio.

${ }^{5}$ Turnout ratios differ from the turnout rate because of migration and voter file attenuation, and thus are not directly interpretable. However as long as this migration and attenuation is orthogonal to date of birth, the percent difference in the turnout ratios should be the same as the percent difference in the turnout rates. Thus, the dependent variables are logged in all analyses so that the results can be interpreted as an effect on the turnout rate.
} 
Let $p$ be the probability that eligible individuals (e.g. $Z_{i}=1$ ) vote in time period 1 . For eligible individuals $\hat{Y}_{i, 1}=p$, while for ineligible individuals $\hat{Y}_{i, 1}=0$. Therefore, if I estimate the reduced form of Equation 2:

(4) $Y_{i, 2}=\alpha_{2}+\beta_{2} X_{i, 2}+\psi Z_{i}+\varepsilon_{i, 2}$,

by OLS, then $\mathrm{E}[\hat{\psi}]=\theta p$. This suggests if I can estimate $p$ from a data source other than the CSVF, then I can approximate $\hat{\theta}=\hat{\psi} / \hat{p}$. This illustrates a well known property of IV with a single instrument; the IV point estimate is the same as OLS estimate of the reduced form effect of the instrument on $Y_{i, 2}$ divided by OLS estimate of the first-stage effect of the instrument on $Y_{i, 1}$.

Figures 1 and 2 illustrate the empirical strategy. Define the 2000-eligible cohort as those individuals born between September 21, 1982 and November 1, 1982 and the 2000-ineligible cohort as those individuals born between November 9, 1982 and December 20, 1982. Figure 1 shows how the 2004 turnout ratio differs between the cohorts of people who turned eighteen in the six week window before and after election week in 2000. ${ }^{6} \quad$ The first panel in Figure 1 compares the number of 2004 voters by week of birth. This panel shows that 8.9 percent more individuals participated in the 2004 election in the 2000-eligible cohort than the 2000-ineligible cohort. The second and third panels of Figure 1 show that the greater number 2000-eligible participants can only partially be explained by the size of the underlying population. Although slightly more individuals were born in California in the 2000-eligible than the 2000-ineligible cohort,

\footnotetext{
${ }^{6}$ Election week refers to the week of November 2-8 on which all federal elections occur. Data from this week are excluded from the figures to keep the control group constant across elections; however, it is included in the statistical analysis in the next section.
} 
the ratio of participants to births is greater in the eligible cohort. A ratio of 0.272 for the 2000-eligible cohort, compared to 0.261 for the 2000-ineligible cohort, suggests 2000eligible citizens are 4.1 percent more likely than 2000-ineligible citizens to vote in 2004.

To interpret the simple difference in participation presented in Figure 1 as a causal effect, however, requires the assumptions that there are no other differences between individuals born pre- and post-election-week that may affect their subsequent participation. This may not be correct if, for example, educational attainment is consistently higher among individuals in the pre-election week cohorts due to schooling age restrictions, causing eligible cohorts to have greater participation rates that do not result from past election eligibility.

Figure 2 shows the behavior of a control group - individuals who turned eighteen just before and after election week in odd years between 1987 and 2001. Because no elections occur during election week in odd years, these cohorts do not differ with respect to past election eligibility. As a result, I can adopt a difference-in-difference (DD) framework that compares the difference in participation between pre- and post-election week cohorts when the two cohorts differ in past eligibility with the difference between pre- and post-election week cohorts when the two cohorts do not differ in past election eligibility. The bottom panel of Figure 2 indicates that the average ratio of participation to births is 0.352 in the pre-election week cohort and 0.348 in the post-election week cohort. Under the assumption that the effect of past eligibility is proportional to turnout, the difference-in-difference estimate of the increase in the probability of voting resulting from 2000 eligibility $\lambda^{*}$ is therefore

$$
\lambda^{*}=(\ln (0.272)-\ln (0.261))-(\ln (0.352)-\ln (0.348))=0.030
$$


or 3.0 percent. $^{7}$

To formalize this intuition, let $T_{d, y}$ be the number of individuals participating in the 2004 presidential election who turn eighteen on day $d$ in year (or cohort) y. Let $P o p_{d, y}$ be the number of potential voters who turn eighteen on day $d$ in year $y$. If an election occurs in year $y$, only those individuals born prior to day $\bar{d}$ are eligible to vote in this election. Define $\lambda_{y}$ as a year fixed effect, $I\left(d<\bar{d}_{y^{\prime}}\right)$ as an indicator equal to one if a date $d$ occurs prior to election day $\bar{d}$ in year $y^{\prime}$, and $I\left(y=y^{\prime}\right)$ as an indicator equal to one if year $y$ is equal to $y$ '. The DD estimate of the percent change in 2004 turnout caused by 2000 eligibility, $\lambda^{*}$, can be obtained by running OLS on Equation 5:

(5) $\ln \left(T_{d, y} / \operatorname{Pop}_{d, y}\right)=\lambda_{y}+\lambda_{d} I\left(d<\bar{d}_{2000}\right)+\lambda^{*} I\left(d<\bar{d}_{2000}\right) I(y=2000)+\eta_{\mathrm{d}, \mathrm{y}}$, where $y=\{(1987,1989,1991 \ldots, 2001), 2000\} .{ }^{8}$ Equation 5 is identified because no statewide elections occur in California in any odd years in the dataset. Put another way, because individuals who turn eighteen before and after election week in odd numbered years are no different in terms of election exposure, the difference in pre- and postelection-week cohorts' political participation absent voting-age restrictions can be estimated.

However, I do not observe $P o p_{d, y}$ but only $B_{d, y}$, the number of births. To account for this, I rewrite Equation 5 as:

\footnotetext{
${ }^{7}$ I obtain a slightly larger point estimate if I use individuals who turned eighteen in 1999 and 2001 rather than all odd years as the control group. In this control group the turnout ratio is 0.269 in the pre-election week cohort and 0.268 in the post-election week cohort.

${ }^{8}$ Observations from 2003 are excluded because of the special California recall election.
} 


$$
\begin{aligned}
& \ln \left(\left(T_{d, y} / B_{d, y}\right)\left(B_{d, y} / \operatorname{Pop}_{d, y}\right)\right)= \\
& \lambda_{y}+\lambda_{d} I\left(d<\bar{d}_{2000}\right)+\lambda^{*} I\left(d<\bar{d}_{2000}\right) I(y=2000)+\eta_{\mathrm{d}, \mathrm{y}},
\end{aligned}
$$

or

$$
\text { (7) } \ln \left(\left(T_{d, y} / B_{d, y}\right)\right)=\lambda_{y}+\lambda_{d} I\left(d<\bar{d}_{2000}\right)+\lambda^{*} I\left(d<\bar{d}_{2000}\right) I(y=2000)+v_{\mathrm{d}, \mathrm{y}} \text {, }
$$

where $v_{\mathrm{d}, \mathrm{y}}=\eta_{\mathrm{d}, \mathrm{y}}+\ln \left(B_{d, y} /\right.$ Pop $\left._{d, y}\right)$.

As long $\ln \left(B_{d, y} / P o p_{d, y}\right)$ is independent of the covariates, OLS estimates of $\lambda^{*}$ from Equation 7 are consistent. In other words, as long as the measurement error in the approximation of the size of the eligible voting population is independent of the day of birth, the effect of voting restrictions on subsequent voting behavior can be estimated without knowing the exact size of the eligible voting population.

To investigate the validity of this assumption, I estimate a variant of Equation 5 that parameterizes the heterogeneity in population instead of adjusting for it with the number of births. This model replaces $\ln \left(T_{d, y} / P_{o p_{d, y}}\right)$ with $\ln \left(T_{d, y}\right)$ :

$$
\begin{aligned}
& \ln \left(T_{d, y}\right)= \\
& \lambda_{y}+\lambda_{d} I\left(d<\bar{d}_{2000}\right)+\lambda^{*} I\left(d<\bar{d}_{2000}\right) I(y=2000)+\left(\eta_{d, y}+\ln \left(P_{o p_{d, t}}\right)\right)
\end{aligned}
$$

and specifies heterogeneity in population as a linear combination of birth-day-specific, cohort-specific, and birth-day-of-the-week-specific fixed effects: ${ }^{9}$

(9) $\ln \left(\operatorname{Pop}_{d, y}\right)=\gamma_{d}+\gamma_{y}+\gamma_{i}(W(d, y)=i)+v_{\mathrm{d}, \mathrm{y}}$,

where $W(t, y)$ is a function that returns the day of the week of birth for people born on day $d$ in year $y$. In this model, $\lambda^{*}$ can be identified by estimating Equation 10 by OLS:

\footnotetext{
${ }^{9}$ Days of the week fixed effects are needed because fewer births occur on weekends than on weekdays.
} 
(10) $\ln \left(T_{d, y}\right)=\theta_{d}+\theta_{y}+\gamma_{i}(W(d, y)=i)+\lambda^{*} I\left(d<\bar{d}_{2000}\right) I(y=2000)+\xi_{\mathrm{d}, \mathrm{y}} \cdot$

As long as the differences in the eligible voting population within the event window are constant across years, OLS estimates of Equation 10 provide consistent estimates of the effects of eligibility.

Equations 7 and 10 each have certain advantages. Both are difference-indifference specifications, meaning they compare the difference in pre- and post-electionweek turnout between the cohort who turns eighteen in the treatment year (i.e. 2000) versus the control years (i.e. odd years). The advantage of Equation 7 is that it depends on weaker parametric assumptions. In addition, Equation 7 may be more efficient if $B_{d, y}$ captures substantial variation in the number of potential voters. The trade-off is that Equation 10 does not require any auxiliary information about cohort sizes. Equation 10 also cannot be biased by systematic errors in the measurement of the population size that could occur due to migration.

I obtain my basic results by estimating Equations 7 and 10 using day $d=$ $(9 / 21, \ldots, 12 / 20)$ via OLS. $^{10}$ Also, I estimate four variants of Equations 7 and 10. First, I investigate whether 2002 midterm eligibility affects 2004 turnout; these models replace $I\left(d<\bar{d}_{2000}\right) I(y=2000)$ with $I\left(d<\bar{d}_{2002}\right) I(y=2002) . .^{11}$ Second, I test whether 2000 or 2002 eligibility affects party affiliation; these models replace $\ln \left(T_{d, y} / B_{d, y}\right)$ with $\ln \left(P_{d, y} / T_{d, y}\right)$ in Equation 7, where $P_{d, y}$ is the number of voters registered with a given political party. Third, I check whether 2000, 2002, 2004, and 2005 election eligibility affects 2006 turnout; these models define $T_{d, y}$ as the number of individuals voting in the

\footnotetext{
${ }^{10} \mathrm{I}$ demonstrate later that results are generally robust to the size of the window.

${ }^{11}$ The sample is also changed to be $\mathrm{y}=\{(1987,1989,1991 \ldots, 2001), 2002\}$.
} 
2006 midterm election and include $I\left(d<\bar{d}_{2000}\right) I(y=2000), I\left(d<\bar{d}_{2002}\right) I(y=2002)$, $I\left(d<\bar{d}_{2004}\right) I(y=2004)$, or $I\left(d<\bar{d}_{2005}\right) I(y=2005)$ to measure the effect of eligibility in 2000, 2002, 2004, and 2005 respectively. Finally, I examine whether eligibility in any elections prior to 2000 continues to significantly affect 2004 participation; these models capture the effect of eligibility to vote in year $\hat{y}$ by including $I\left(d<\bar{d}_{\hat{y}}\right) I(y=\hat{y})$.

\section{Results}

2004 Participation

Table 1 presents estimates of the change in the probability of 2004 participation resulting from 2000 presidential election eligibility. Using either Equation 7 or 10, 2000 eligibility significantly increases the likelihood of 2004 participation. Estimates of $\lambda^{*}$ from Equation 10 in Column 1 indicate that voting eligibility in 2000 increases the likelihood of 2004 participation by 4.5 percent, while estimates from Equation 7 in Column 2 show the effect to be 3.0 percent. $^{12}$ In both specifications, the coefficient on 2000 eligibility is significant at the 5 percent level. Table 1 also presents estimates of the change in the probability of 2004 participation resulting from 2002 presidential election eligibility. Eligibility in 2002 is found to have an insignificant effect on 2004 participation using both specifications.

The estimates of $\lambda^{*}$ in Table 1 capture the intent-to-treat effect of 2000 participation in percent terms. These estimates can be transformed to approximate $\theta$ from Equation 2, which represents the treatment-on-the-treated effect of 2000

\footnotetext{
${ }^{12}$ I obtain similar estimates of $\lambda^{*}$ if I restrict the sample to $\mathrm{y}=\{1999,2000,2001\}$. I estimate $\lambda^{*}=0.041$ (s.e. 0.015) using Equation 10 and 0.038 (s.e. 0.017) using Equation 7.
} 
participation on 2004 participation. First note that $p_{2004}^{\text {elig }}=(1+\lambda) p_{2004}^{\text {inelig }}$, where $p_{2004}^{\text {elig }}$ and $p_{2004}^{\text {inelig }}$ are the percentage of 2000-eligibles and 2000-ineligibles voting in 2004 . Thus, the percentage point increase in 2004 turnout from 2000 -eligibility is $\lambda p_{2004}^{\text {inelig }}$. Let $p_{2000}^{\text {elig }}$ be the percentage of 2000-eligibles voting in 2004. Under the assumption that the effect of 2000 eligibility on 2004 participation is only through the channel of 2000 participation, the resulting mapping is $\theta=\lambda^{*} p_{2004}^{\text {inelig }} / p_{2000}^{\text {elig }}$.

Unfortunately we do not observe either $p_{2000}^{\text {elig }}$ or $p_{2004}^{\text {inelig }}$ in the CSVF. Instead I use turnout data from the 2000 and 2004 November CPS Voter Supplements to approximate $p_{2000}^{\text {elig }}$ and $p_{2004}^{\text {inelig }}$. I approximate $\hat{p}_{2000}^{\text {elig }}=0.293$ using turnout rates for Californian citizens age 18 and 19 in the 2000 election. Similarly, I approximate $\hat{p}_{2004}^{\text {inelig }}=0.486^{13}$ using data for Californian citizens age 20 and 21 in 2004 presidential elections. ${ }^{14}$ Using estimates of $\lambda^{*}$ from Column 1 of Table 1 , I approximate that

$$
\hat{\theta}=\frac{\hat{\lambda}^{*} \hat{p}_{2004}^{\text {inelig }}}{\hat{p}_{2000}^{\text {elig }}}=\frac{(0.045)(0.486)}{0.293}=0.075,
$$

\footnotetext{
${ }^{13}$ Note that this value is substantially different than the turnout ratio of 0.261 found for this group in the bottom panel of Table 1. This difference reflects the joint effects of voting history attenuation in the CSVF, migration of individuals out of their states of birth, and the over-reporting of turnout in the CPS. ${ }^{14}$ The relatively large difference between $p_{2000}^{\text {elig }}$ and $p_{2004}^{\text {inelig }}$ captures both a substantial increase in reported turnout among young citizens between the 2000 and 2004 elections and age effects. Nationwide reported turnout in 2004 for citizens age 18 to 24 is 46.7 percent, compared to 36.1 percent in 2000 . Nationwide reported turnout rates for citizens age 18 and 19 are 30.6 and 43.9 in 2000 and 2004 respectively, while nationwide reported turnout rates for citizens age 20 and 21 are 34.5 and 47.9 in 2000 and 2004 respectively.
} 
or that voting in 2000 increases the probability of voting in 2004 by 7.5 percentage points. Performing the same calculation using the estimate in Column 2 of Table 1 approximates the same effect to be 5.0 percentage points.

I also test whether 2000 or 2002 eligibility affects the partisan affiliations of 2004 participants. Table 2 presents estimates using Equation 5 of the percent change in the probability that 2004 voters in the pre- and post-election-week cohorts affiliate with political parties resulting from 2000 and 2002 eligibility. Table 2 indicates that eligibility to vote in 2000 significantly affects the partisan affiliation of 2004 voters. 2000-eligible voters are 2.7 percent more likely to be registered with a party and 5.8 percent more likely to be registered as a Democrat. This implies about a two percentage point increase both in being registered with a party and being registered as a Democrat. Again no significant effect of 2002 eligibility is found on partisan affiliations.

Three potential explanations exist for the finding that 2000-eligible voters are more likely to be affiliated as Democrats. First, eligibility in 2000 may have increased the turnout of Democrats more than Republicans. Alternatively, eligibility in 2000 may have increased the likelihood that voters affiliate with the Democratic Party. Finally, differences in partisan affiliations may result from 2000-eligible voters being more likely to be registered prior to the any partisan realignment that resulted from the events of September 11, 2001.

\section{Participation}

I also test the effect of past election eligibility on 2006 midterm election participation. This allows me to also examine whether eligibility to participate in the 
2004 presidential or the 2005 special California statewide elections affected the likelihood of participation in 2006. Figure 3 replicates the type of analysis in the bottom panels of Figures 1 and 2 for 2006 midterm election participation. Figure 3 indicates that the 2006 turnout ratio is again larger for the 2000-eligibles than the 2000-ineligibles. In addition, Figure 3 demonstrates that 2004 presidential eligibility substantially increased turnout in the 2006 midterm election. The turnout ratio of the 2004-eligible cohort is 0.134 compared to 0.108 for the 2004-ineligible cohort, implying a difference-indifference estimate of the increase in 2006 participation resulting from 2004 eligibility of

$$
\lambda^{*}{ }_{2004}=(\ln (0.134)-\ln (0.108))-(\ln (0.248)-\ln (0.245))=0.204,
$$

or 20.4 percent.

Table 3 presents estimates of $\lambda^{*}$ from Equations (5) and (8) that test the significance of the patterns observed in Figure 3. Both Equations are estimated separately using years $\mathrm{y}=\{(1987,1989,1991 \ldots, 2001), \hat{y}\}$ for $\hat{y}=\{2000,2002,2004$, 2005\}. Table 3 again indicates that past presidential election eligibility significantly increased the likelihood of subsequent participation. As demonstrated above, 2004eligibility increased 2006 participation by about 20 percent. In addition, point estimates show that 2000-eligibility increased 2006 participation by 3.1 to 4.6 percent. $^{15}$

To use the estimates of $\lambda^{*}$ in Table 3 to approximate the treatment-on-the-treated increase in 2006 participation caused by 2004 participation, I need measures of the 2004 turnout rate for 2004-eligibles and the 2006 turnout rate for 2004-ineligibles. I do this by

\footnotetext{
${ }^{15}$ I also estimate the effect of 2000 eligibility on 2002 participation. I find $\lambda^{*}=0.114$ (s. e. 0.028 ) using Equation 7 and 0.101 (s. e. 0.029) using Equation 10. However, there is substantial voter history attenuation from the CSVF that makes this analysis conditional on remaining in the voter file for three years. Thus, these number are not directly comparable with the effect of 2004 eligibility on 2006 participation
} 
using CPS turnout data for Californian citizens age 18 and 19 in the 2004 and 2006 elections. These data indicate that 37.5 and 19.1 percent of California citizens age 18 and 19 participated in the 2004 and 2006 election respectively. Using estimate of $\lambda^{*}$ from Column 5, I approximate that:

$$
\hat{\theta}_{2004}=\frac{(0.221)(0.191)}{0.375}=0.113 \text {, }
$$

or that voting in 2004 increased the probability of voting in 2006 by 11.3 percentage points. Performing the same calculation using the estimate in Column 6 of Table 3 approximates the effect to be 10.0 percentage points. ${ }^{16}$

In contrast, neither 2002 midterm nor 2005 special election eligibility significantly affects 2006 participation. The differential effects resulting from 2002 or 2005 election eligibility relative to 2000 and 2004 presidential election eligibility suggest a heterogeneous effect of past participation. Specifically, it suggests that the subsequent turnout decisions of those individuals participating in low salience elections are less affected by past participation. One explanation for this finding is that the types of individuals participating in low salience elections are already likely to be participating in subsequent elections absent any reinforcement. If past participation affects future participation by slightly lowering the costs or raising the benefits of voting, then those voters who are marginal with respect to future participation are those who should be primarily affected by past participation. According to the November CPS Voter Supplement, only 18.8 percent of California citizens between the ages of eighteen and

\footnotetext{
${ }^{16}$ Going through the same exercise to find the effect of participation in 2000 on 2006 participation shows voting in 2000 increased the probability of voting in 2006 by between two to three percentage points.
} 
twenty-four reported participating in the 2002 midterm election. ${ }^{17}$ In comparison, 37.2 and 44.9 percent reported voting in the 2000 and 2004 presidential elections respectively. Because most of the 18.8 percent of young citizens that voted in 2002 are likely to vote in the subsequent presidential elections, a ceiling exists on the affect of past participation. ${ }^{18}$ In contrast, some of the less politically engaged of the 37.2 percent of young citizens participating in the 2000 election are likely to be marginal with respect to future participation. It is the subsequent turnout decisions of these voters that appear to be affected by past turnout.

The null effect of 2005 eligibility on 2006 participation also is suggestive about the role of registration as mechanism for the results observed in Table 1 and Table 3. One way in which past eligibility may affect subsequent participation is that past eligibility increases the likelihood of being registered to vote, which in turn increases the likelihood of voting. To test the effects of eligibility on registration, I estimate a variant of Equation 7 replacing the number of voters with the number of registrants. I find that the number of registered voters in 2006 substantially increases from $2000\left(\lambda^{*}=0.024\right.$, s.e. 0.012$), 2004\left(\lambda^{*}=0.309\right.$, s.e. 0.009$)$ and $2005\left(\lambda^{*}=0.068\right.$, s.e. 0.010$)$ eligibility. Thus, while eligibility in all of these elections significantly increases registration, I only observe increases in turnout following elections with high participation. This is suggestive that increased registration is not a primary mechanism causing past eligibility to increase subsequent turnout.

\footnotetext{
${ }^{17}$ While CPS data is unavailable for 2005, the California Secretary of State estimates that statewide turnout was approximately the same in 2002 and 2005 (36.06 in 2002 versus 35.44 in 2005).

${ }^{18}$ Cho (2008) shows that at least 82.5 percent of all 2002 midterm voters in Los Angeles County also voted in the 2000 presidential election. Unfortunately, my copies of the CSVF are too outdated to perform similar calculations for the entire state or for young voters specifically.
} 


\section{Long-run Effects}

In this section I investigate if election eligibility prior to 2000 affected 2004 participation or partisan affiliations. Voting in the 2000 presidential election may have had unique effects on voter behavior because of the extraordinary circumstances surrounding its resolution. Therefore, I want to estimate whether similar effects result from other elections. Using both Equations 7 and 10, I estimate $\lambda_{\hat{y}}^{*}$, which is the percent increase in likelihood of 2004 participation resulting from eligibility in year $\hat{y}$, for $\hat{y}=$ $\{1988,1990,1992,1994,1996$, and 1998\}.

Table 4 presents the effects of election eligibility prior to 2000 on 2004 participation. There is some evidence that eligibility in presidential elections prior to 2000 affected 2004 participation. Using Equation 10, eligibility in 1992 (but not 1996) is found to significantly increase 2004 participation, while using Equation 7 eligibility in 1996 (but not 1992) is found to significantly increase participation. In no specification are any of the coefficients on midterm or special election eligibility significant.

There are many potential mechanisms for these long-run effects observed in Table 4. Each instance of voting may further reduce the cost of future voting, although this cost reduction may be decreasing in the number of instances of voting. Alternatively, the increased participation in 2000 resulting from 1996 eligibility may increase turnout in 2004. Without a structural model, I cannot differentiate between these (and other) potential mechanisms.

Table 5 presents estimates of the effects of election eligibility prior to 2000 on the partisan affiliations of 2004 participants. To ensure that any differences in partisan affiliation do not result from temporal differences in registration, the sample is restricted 
only to those 2004 voters who registered to vote after the 2000 presidential election. The results in Table 5 indicate that past eligibility significantly affects the partisan affiliations of 2004 voters. Eligibility in the 1996 presidential election significantly increases the likelihood of registering with a political party by 2.2 percent. ${ }^{19}$ Such a finding is consistent with learning models like Achen (2006), where partisanship is learned through past voting experiences.

\section{Alternative Windows}

One potential concern about the results is that they are unique to the six week window around election week. To further explore the validity of these results, I investigate how past eligibility affects turnout using different windows around the eligibility cutoff date. Figure 4 presents point estimates and 95 percent confidence intervals for the effect on 2000 eligibility on 2004 turnout using a range of windows around election week. Figure 4 indicates that similar point estimates are found when using three, four, five, six, or seven week windows, although the precision of the estimates increases with the size of the window.

Another concern about results identified in narrow windows around the discontinuity is that the effects might be unique to first year college students who arrive right before a presidential election. Figure 5 shows the turnout ratio by birth month in the eighteen month window around the 2000-eligibilty cutoff. ${ }^{20}$ Figure 5 shows that the discontinuity identified in the smaller windows is also present with an eighteen-month

\footnotetext{
${ }^{19}$ Table 5 also shows that 1994 midterm election eligibility significantly increased the probability of Democrat affiliation, although this result in not robust to choice of window around election week.

${ }_{20}$ Citizens born between November $1^{\text {st }}$ and November $7^{\text {th }} 1982$ were eligible to vote in 2000, but are included in an ineligible cohort in Figure 3 to simplify notation.
} 
window. For example, the turnout ratio for the cohort of individuals born between August and October of 1982 (e.g. eligible to vote in 2000) is 0.274 , compared to 0.261 for the cohort of individuals born between November, 1982 and January, 1983 (e.g. eligible to vote in 2000).

Simply comparing the average turnout of all eligible cohorts to the average of ineligible cohorts, however, conflates the effect of age with that of eligibility. With a sixweek window, it is reasonable to assume that the effect on turnout of the difference in eligibles' versus ineligibles' age is negligible; with an eighteen-month window, this assumption is less plausible. To isolate just the effect of eligibility, I assume that the age effect on turnout between eligibles and ineligibles is equal to the effect on turnout between two cohorts of eligibles whose age differs by the same amount. Thus, using individuals born August-October, the effect of eligibility in 2000 is

$$
\begin{aligned}
\lambda_{2000}= & \left(\left(\ln \left(T^{8 / 82-10 / 82}\right)-\ln \left(T^{8 / 83-10 / 83}\right)\right)-\left(\left(\ln \left(T^{8 / 81-10 / 81}\right)-\ln \left(T^{8 / 82-10 / 82}\right)\right)\right.\right. \\
& 2 \ln \left(T^{8 / 82-10 / 82}\right)-\ln \left(T^{8 / 83-10 / 83}\right)-\ln \left(T^{8 / 81-10 / 81}\right)=2 \ln (0.274)-\ln (0.281)-\ln (0.259)=0.031
\end{aligned}
$$

or 3.1 percent. Similarly, using individuals born November-January, the effect of 2000 eligibility is

$$
\lambda_{2000}=\ln \left(T^{11 / 81-1 / 82}\right)+\ln \left(T^{11 / 83-1 / 84}\right)-2 \ln \left(T^{11 / 82-1 / 83}\right)=\ln (0.277)+\ln (0.258)-2 \ln (0.261)=0.049
$$

or 4.9 percent. These additional estimates of the increase in 2004 participation resulting from 2000 eligibility are similar to those obtained in the six week window.

\section{Conclusion}

Political scientists have long recognized that there are many reasons to expect persistence in turnout. Voting provides citizens with information on the location of their 
polling location and how to fill out a ballot, which can be applied in future elections. Political information gathered on candidate positions in past elections may make it easier to differentiate between candidates in the future. Campaigns are more likely to target those voters with known voting histories. Voting may alter psychological orientations to favor future participation. All of these factors lower the cost of subsequent voting, which should generate persistence.

Yet, surprisingly little empirical work has identified the causal effect of past on current voting. This paper seeks to fill this gap by answering a closely related question: how does past eligibility affect current participation. The paper reports three main findings. First, past presidential election eligibility increases subsequent participation. I find that 2000 eligibility increased the probability of voting in 2004 by 3.0 to 4.5 percent, which suggests that voting in 2000 increased the probability of voting in 2004 by 5.0 to 7.5 percentage points. Similarly I find that 2004 eligibility increased the probability of voting in 2006 by 19.7 to 22.1 percent, which suggests that voting in 2004 increased the probability of voting in 2006 by 10.0 to 11.3 percentage points. In contrast, no effect is found of 2002 midterm or 2005 special election eligibility on subsequent participation. Second, past presidential election eligibility affects partisan identification. I find that 2000 eligibility increased the probability of being registered as a Democrat by two percentage points, while reducing the probability of being registered as an Independent by the same amount. Third, voting-age restrictions continue to affect future participation and partisan identification for several election cycles after a voter first becomes eligible. 1992- and 1996-eligibility marginally increased the likelihood of 2004 participation, while 1996-eligibility increased the likelihood of affiliating with a political party. 
My results have implications for models of political behavior. The finding that 1992-eligibles are marginally more likely than 1992-ineligibles to vote in 2004 contradicts the predictions of Franklin (2004) and Franklin, Lyons, and March (2004). These authors predict that after three election-cycles, participation should be higher for those citizens who became eligible to vote at an older age. They support their hypothesis by showing in cross-county regressions that aggregate turnout decreases as a larger proportion of the electorate is eligible to vote at the age of eighteen. However, my results provide a direct test of their theory that does not rely on ecological inference or the exogeniety of voting-age law changes. Subject to the caveat that my results are from only one U.S. state and one point in time, they suggest that returning the voting-age to twenty-one would be unlikely to significantly increase voter turnout.

My results also have implications about the types of voters who are affected by persistence. I find that only past presidential election eligibility affects subsequent turnout and partisan affiliation decisions. Many participants in these elections are likely to be on-the-fence with respect to future participation. Such individuals' subsequent turnout decisions are likely to be particularly affected by any positive reinforcement that is received from past participation. In contrast, those eighteen year olds who participate in low salience elections are likely to continue to vote in future elections absent any reinforcement. Therefore, my findings suggest that reinforcement from past participation affects the subsequent participation of more marginal voters, who (at least initially) do not participate in less salient elections.

This finding that the reinforcement from past participation affects the turnout decisions of marginal voters has implications for reconciling the previous results of 
Gerber, Green, and Shachar (2003) with those in this paper. Gerber, Green, and Shachar find that voting in the 1998 Connecticut midterm election increases the probability of voting in a local election in 1999 by about fifty percentage points. In contrast, I find estimates in the five to ten percentage point range. Moreover, based on the literature outlined in Section 2, it is expected that persistence would have a greater effect on young individuals being socialized into the political process. However, it is important to remember that Gerber, Green, and Shachar are estimating a LATE for the two percent of their sample that is induced to vote by receiving GOTV targeting. These are by construction marginal voters. $^{21}$ In contrast, I am estimating a LATE for the entire population of young voters. My results therefore suggest that Gerber, Green, and Shachar's estimate for the marginal voter may be an order of magnitude larger than the treatment effect on the broader population. ${ }^{22}$

One critical assumption when transforming my effects of past eligibility on current participation into the effects of past participation on current turnout is that the only channel through which past eligibility affects subsequent turnout is through past participation. This implies that being eligible to vote in 2000 only affects the probability of turnout in 2004 and 2006 through past voting experiences. One problem with such an assumption is that any exogenous treatment to increase voting likelihood is also likely affect voters' subsequent information sets. As a result any instrumental variable approach to estimating persistence is likely capture the joint effect of past voting

\footnotetext{
${ }^{21}$ These individuals also reveal themselves to be able to be mobilized by GOTV activity. To the extent that future GOTV targeting is based on past voting history, this could make the make the effect of past participation particularly large on this subpopulation.

${ }^{22}$ This is not to suggest that the LATE identified by Gerber, Green, and Shachar (2003) is not also one of interest. For example, this would be the relevant treatment effect for evaluating the downstream consequences of GOTV activity by a campaign.
} 
experiences and past information acquisition. ${ }^{23}$ Therefore, the central finding of this paper that past presidential eligibility increases subsequent turnout should be thought of as not only capturing the effect of past participation, but also any persistence in information that helped the individual cast that ballot.

One advantage of using voting-age restrictions to study persistence in turnout is that treatment status can be captured with a single variable that is already contained in many datasets. As a result, the methods used in this paper can be applied across a wide assortment of electoral environments. This should make it possible to design tests that improve our understanding of the mechanisms leading to persistence in voting. For example, one could study how negative campaigns affect the amount of persistence by analyzing the effect of voting eligibility across different elections. Variation in the effects of voting eligibility across states may also be useful for understanding the effects of institutional features like voter registration deadlines. Similarly, variation in the effects of voting eligibility across countries may help to test the effects of electoral systems characteristics. This potential for such widespread application, combined with the ease of tracking treatment status over time, makes voting-age restriction a promising tool for future research.

\footnotetext{
${ }^{23}$ An analogous problem is faced by Gerber, Green, and Shachar (2003) when using GOTV targeting to identify persistence in participation. To identify their model, Gerber, Green, and Shachar assume that being targeted to vote in the 1998 only affects the likelihood of subsequent participation because it increased past participation. This may be violated, for example, if receiving GOTV materials causes recipients to become more politically informed, which subsequently increases the likelihood of voting absent any increase in actual voting propensity.
} 


\section{References}

Achen, Christopher H. 2006. "Expressive Bayesian Voters, their Turnout Decisions, and Double Probit. Emperical Implications of a Theoretical Model.” Princeton University manuscript. Downloaded from the Sociey for Political Methdology: http://polmeth.wustl.edu/retrieve.php?id=630 on July 20, 2009.

Bendor, Jonathan, Daniel Diermeier, and Michael Ting. 2003. “A Behavioral Model of Turnout." American Political Science Review 73: 261-280.

Brody, Richard A. and Paul M. Sniderman. 1977. "From Life Space to Polling Place: The Relevance of Personal Concerns for Voting Behavior.” British Journal of Political Science 7: 337-360.

Butler, David and Donald Stokes. 1969. Political Change in Britain. New York: St. Martin's Press.

Campbell, Angus, Philip E. Converse, Warren E. Miller, and Donald E. Stokes. 1960. The American Voter. New York: John Wiley and Sons, Inc.

Cho, Dustin. 2008. “Concentric Electorates: Relationships between Municipal, Midterm, and Presidential Voters." Yale University manuscript. Downloaded from SSRN: http://ssrn.com/abstract=1402043 on July 20, 2009.

Dee, Thomas S. 2004. “Are Their Civic Returns To Education.” Journal of Public Economics 88: 1697-1720.

Denny, Kenny and Orla Doyle. 2009. “Does Voting History Matter? Analysing Persistence in Turnout.” American Journal of Political Science 53(1): 17-35.

Fowler, James A. 2006. "Habitual Voting and Behavior Turnout." Journal of Politics 65: $335-344$. 
Franklin. Mark N. 2004. Voter Turnout and the Dynamics of Electoral Competition in Established Democracies Since 1945. Cambridge: Cambridge University Press.

Franklin, Mark N., Patrick Lyons, and Michael March. 2004. "Generational Basis of Turnout Decline in Established Democracies.” Acta Politica 39: 115-151.

Gerber, Alan S., Donald P. Green, and Ron Shachar. 2003. "Voting May Be HabitForming: Evidence From a Randomized Field Experiment." American Journal of Political Science 47(3): 540-550.

Goldstein, Kenneth M. and Travis N. Ridout. 2002. "The Politics of Participation: Mobilization and Turnout over Time." Political Behavior 24(1): 3-29.

Green, Donald P. and Ron Shachar. 2000. "Habit Formation and Political Behavior: Evidence of Consuetude in Voter Turnout." British Journal of Political Science 30: 561-575.

Hynam, Herberg H. 1959. Political Socialization. Glencoe, IL: The Free Press.

Imbens Guido W. and Joshua D. Angrist. 1994. "Identification and Estimation of Local Average Treatment Effects." Econometrica 62: 467-475.

Jennings, M. Kent and Gregory B. Markus. 1984. "Partisan Orientations over the Long Haul: Results from the Three-Wave Political Socialization Panel Study." American Political Science Review 78: 1000-1018.

Markus, Gregory B. 1979. “The Political Environment and the Dynamics of Public Attitudes: A Panel Study.” American Journal of Political Science 23: 338-359. Miller, Warren E. 1992. "The Puzzle Transformed: Explaining Declining Turnout.” Political Behavior 14: 1-43. 
Miller, Warren E. and J. Merrill Shanks. 1996. The New American Voter. Cambridge: Harvard University Press.

Mullainathan, Sendhil and Ebonya Washington. 2009. "Sticking With Your Vote: Cognitive Dissonance and Voting.” American Economics Journal: Applied Economics 1: 86-111.

Plutzer, Eric. 2002. "Becoming a Habitual Voter: Inertia, Resources, and Growth in Young Adulthood.” American Political Science Review 96: 41-56.

Sears, Davis O. and Nicholas A. Valentino. 1997. "Politics Matters: Political Events as Catalysts for Preadult Socialization.” American Political Science Review 91: 4565.

Verba, Sidney and Norman H. Nie. 1972. Participation in America. New York: Harper and Row. 
Figure 1a: Number of 2004 Californian Election Participants by Week of Birth

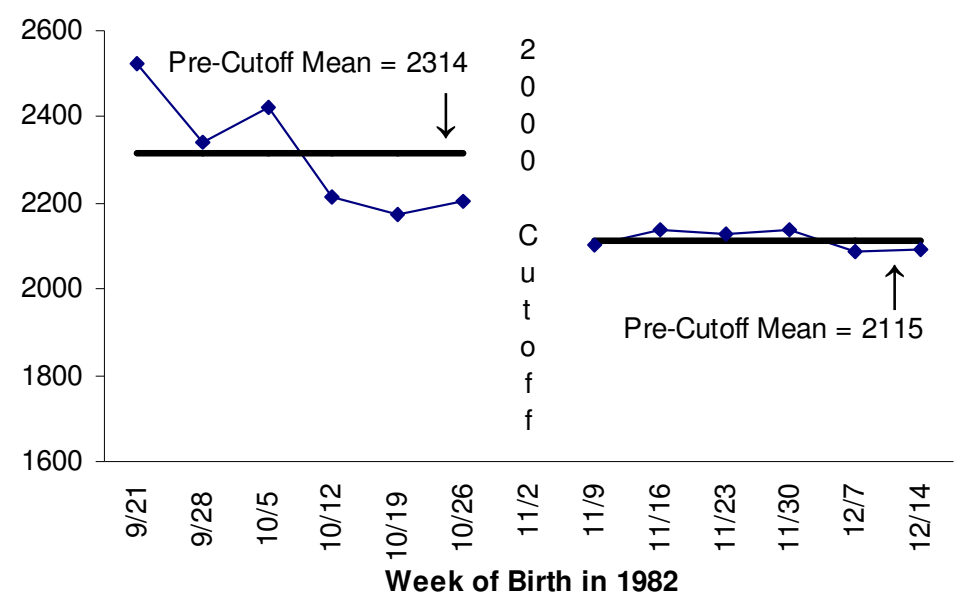

Figure 1b: Number of California Births in Natality File by Week of Birth

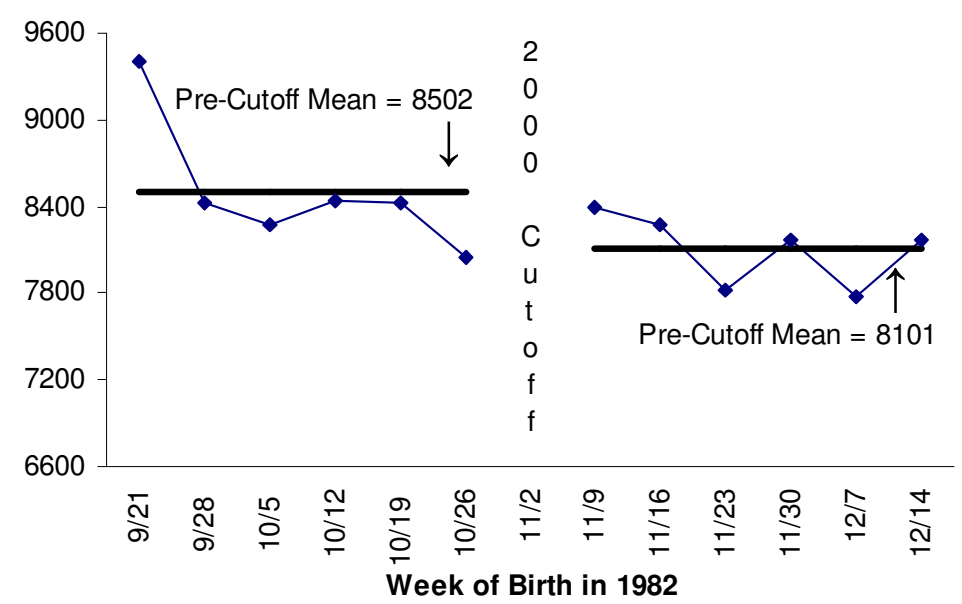

Figure 1c: 2004 Turnout Ratio in California by Week of Birth

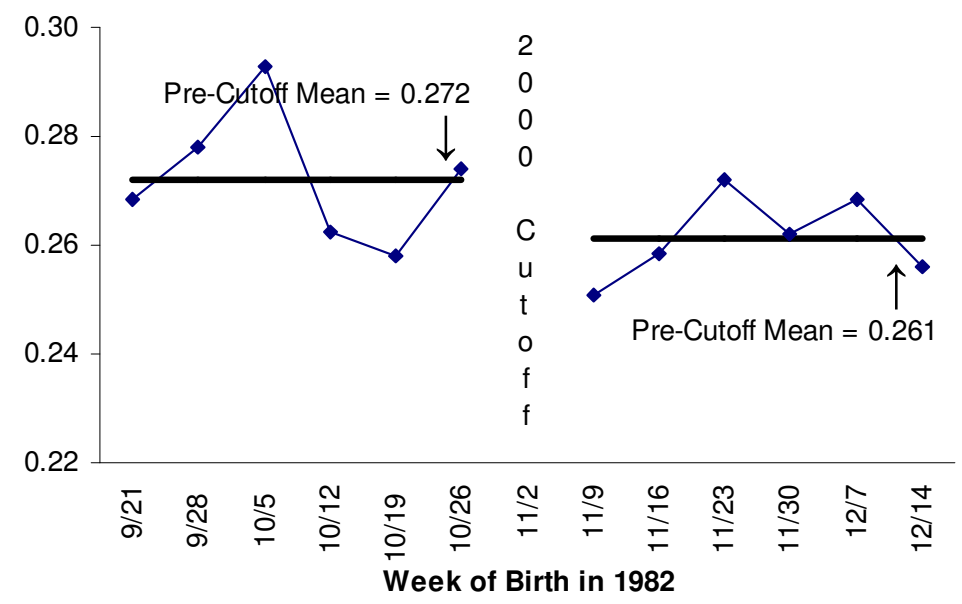


Figure 2a: Number of 2004 Californian Election Participants by Week of Birth

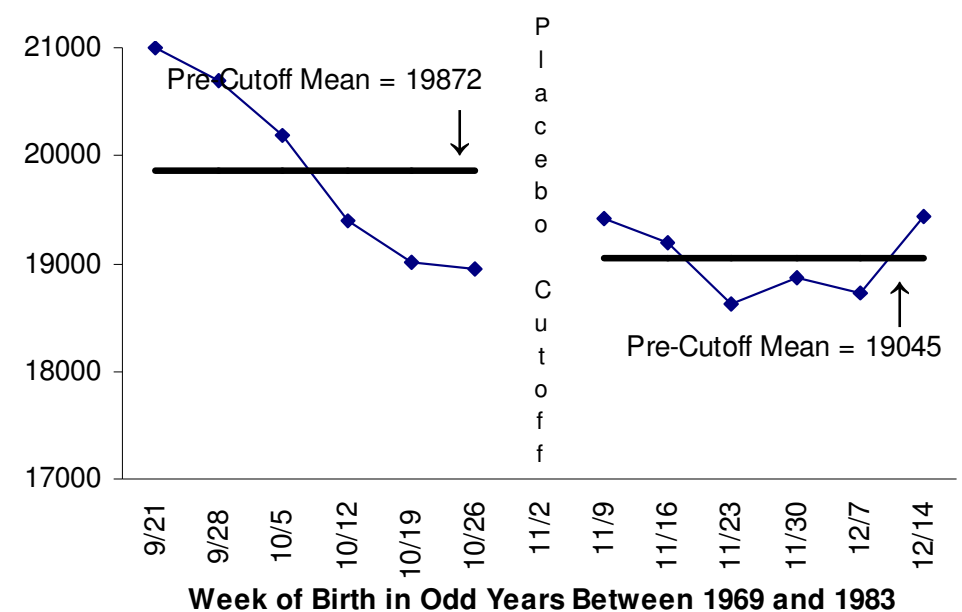

Figure 2b: Number of California Births in Natality File by Week of Birth

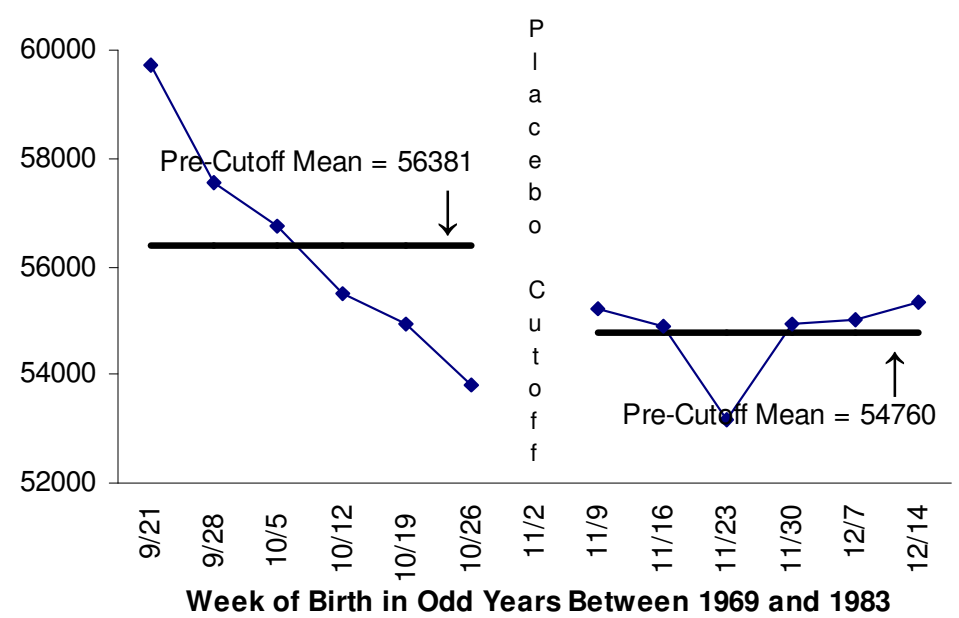

Figure 2c: 2004 Turnout Ratio in California by Week of Birth

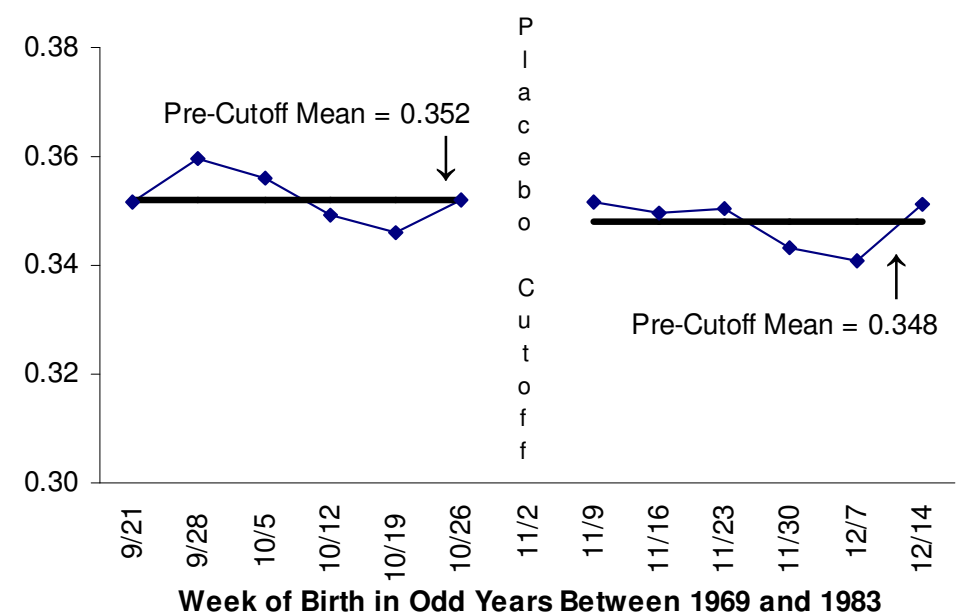


Figure 3: Turnout Ratios in 2006 California Midterm Election
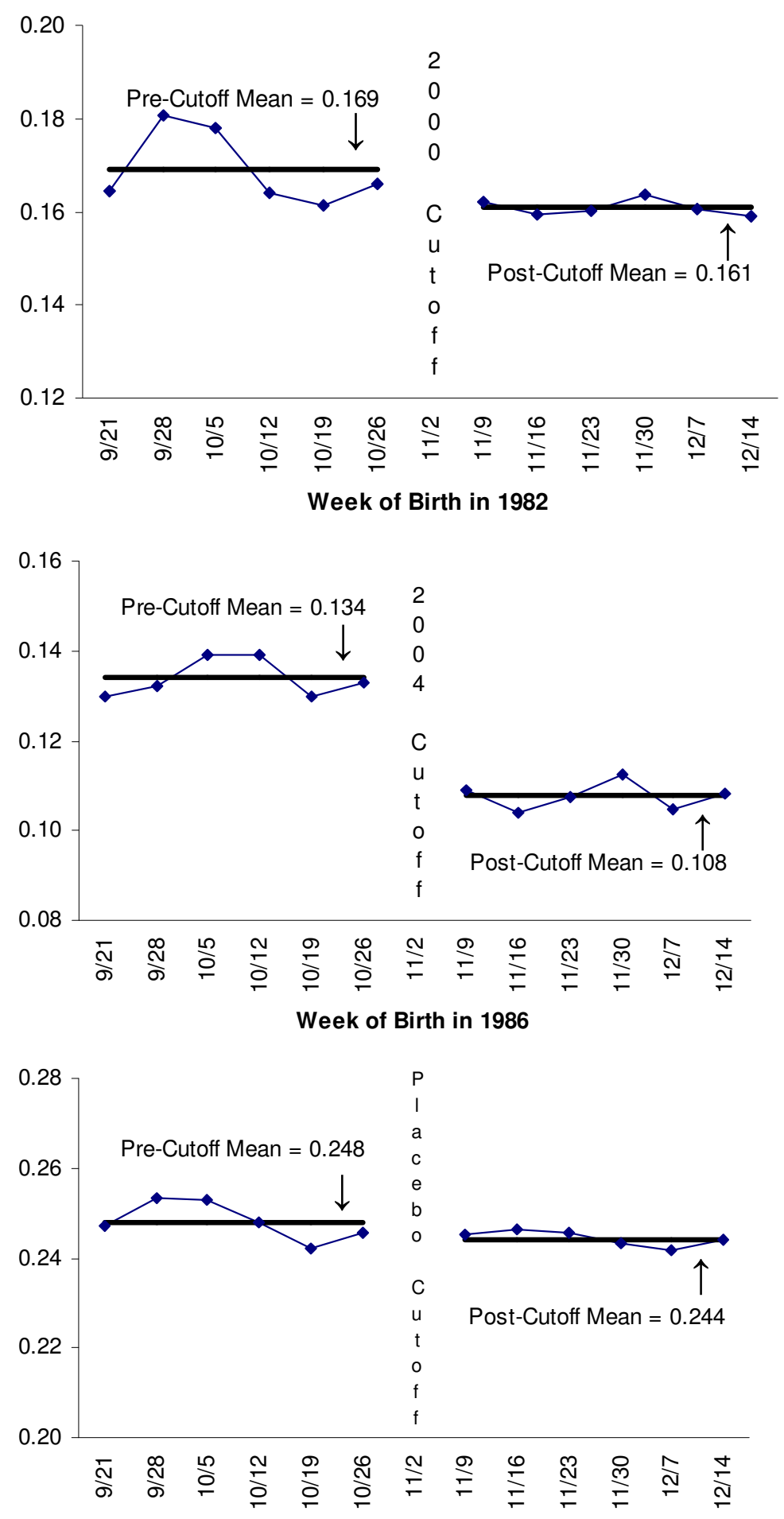

Week of Birth in Odd Years Between 1969 and 1983 
Figure 4: 95\% Confidence Intervals on the Effect of 2000 Eligibility on 2004 Participation by Size of Window around Election Week

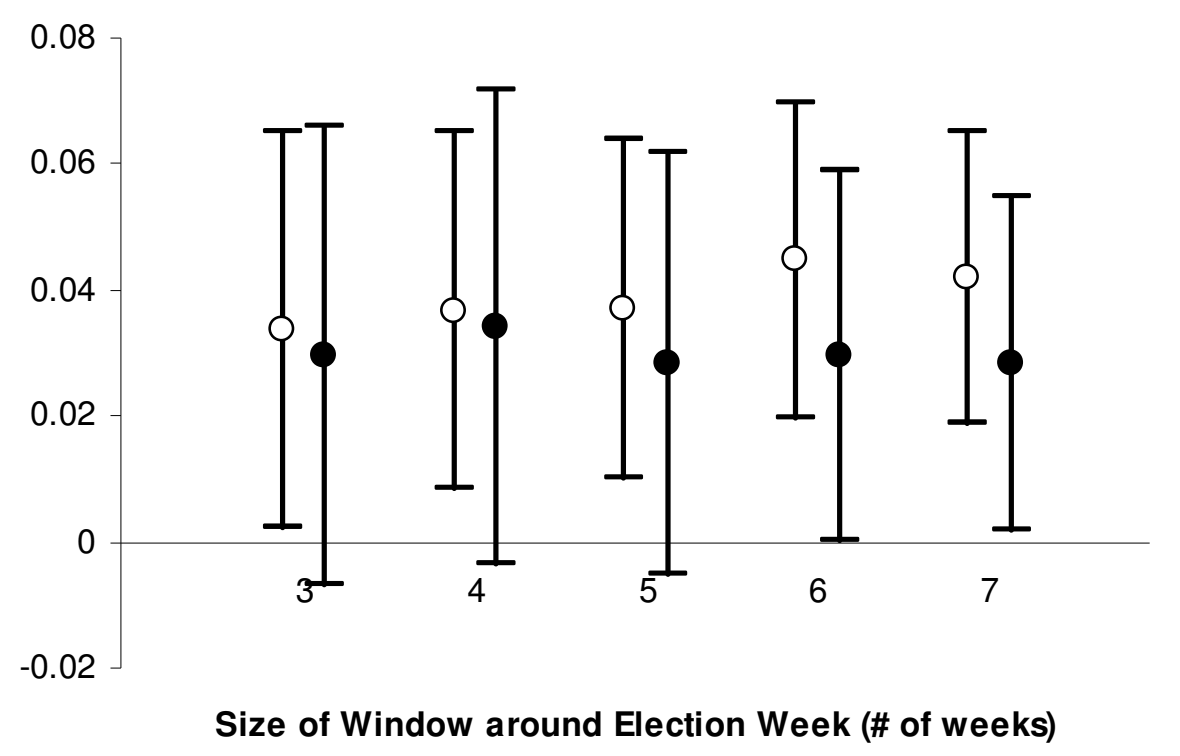

White circles are point estimates from Equation 10; black circles are point estimates from Equation 7. 
Figure 5: Turnout Ratio by Month of Birth in 2004 California Presidential Election

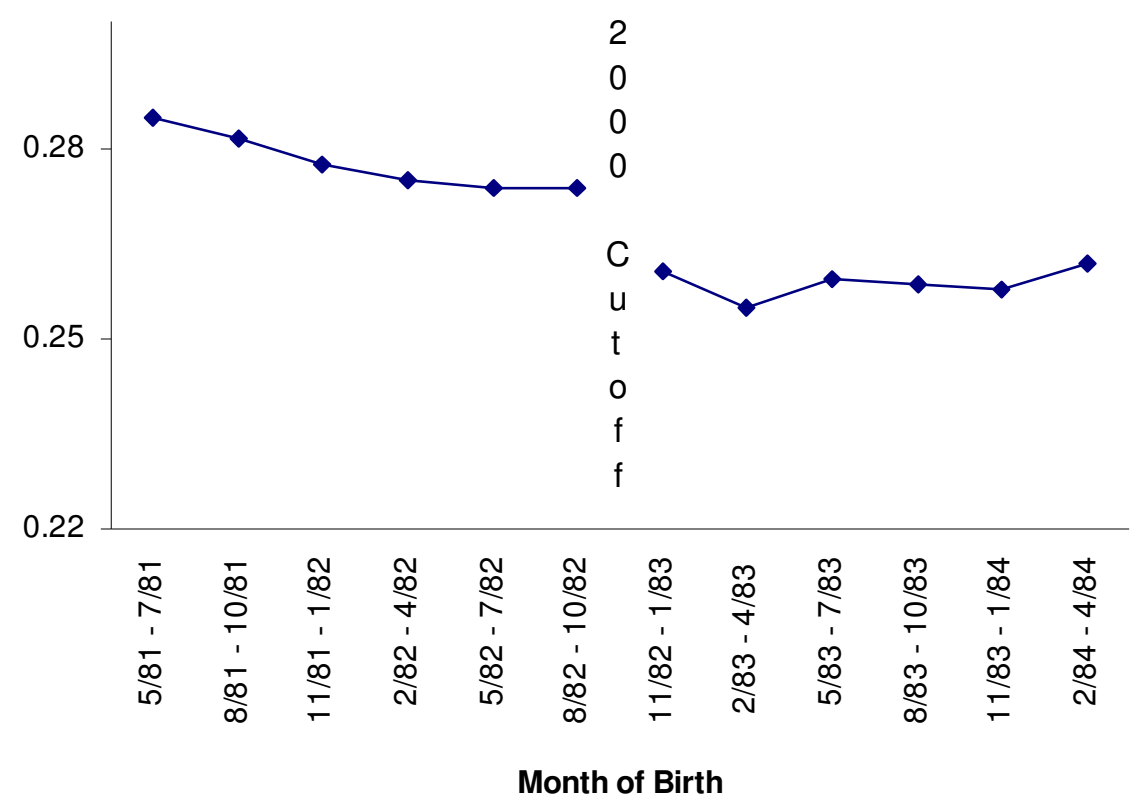


Table 1: Percent Change in 2004 Turnout Resulting from 2000 and 2002 Eligibility

\begin{tabular}{|l|c|c|c|c|}
\cline { 2 - 5 } \multicolumn{1}{c|}{} & $\begin{array}{c}(1) \\
\text { Fixed } \\
\text { Effects }\end{array}$ & $\begin{array}{c}(2) \\
\text { California } \\
\text { Births }\end{array}$ & $\begin{array}{c}\text { Fixed } \\
\text { Effects }\end{array}$ & $\begin{array}{c}(4) \\
\text { California } \\
\text { Births }\end{array}$ \\
\hline \hline 2000 Eligibility & 0.045 & 0.030 & & \\
& $(0.013)$ & $(0.015)$ & & \\
2002 Eligibility & & & -0.004 & -0.016 \\
& & & $(0.015)$ & $(0.015)$ \\
\hline
\end{tabular}

Robust standard errors in parentheses. 
Table 2: Percent Change in Party Affiliation of 2004 Participants Resulting from 2000 and 2002 Eligibility

\begin{tabular}{|l|c|c|c|c|}
\cline { 2 - 5 } \multicolumn{1}{c|}{} & $(1)$ & $(2)$ & $(3)$ & $(4)$ \\
Party Affiliation & Any & Democrats & Any & Democrats \\
\hline \hline 2000 Eligibility & 0.027 & 0.058 & & \\
& $(0.007)$ & $(0.015)$ & & \\
2002 Eligibility & & & 0.006 & 0.023 \\
& & & $(0.008)$ & $(0.015)$ \\
\hline
\end{tabular}

All coefficients estimated by replacing the dependent variable in Equation 7 with the percentage of 2004 participants born on day $\mathrm{d}$ in year $\mathrm{y}$ affiliating with a given party. Robust standard errors in parentheses. 
Table 3: Percent Change in 2006 Turnout Resulting from 2000, 2002, 2004, and 2005 Eligibility

\begin{tabular}{|c|c|c|c|c|c|c|c|c|}
\hline Population Control & $\begin{array}{c}\text { (1) } \\
\text { Fixed } \\
\text { Effects }\end{array}$ & $\begin{array}{c}\text { (2) } \\
\text { California } \\
\text { Births }\end{array}$ & $\begin{array}{c}(3) \\
\text { Fixed } \\
\text { Effects }\end{array}$ & $\begin{array}{c}\text { (4) } \\
\text { California } \\
\text { Births }\end{array}$ & $\begin{array}{c}(5) \\
\text { Fixed } \\
\text { Effects }\end{array}$ & $\begin{array}{c}(6) \\
\text { California } \\
\text { Births }\end{array}$ & $\begin{array}{c}(7) \\
\text { Fixed } \\
\text { Effects }\end{array}$ & $\begin{array}{c}(8) \\
\text { California } \\
\text { Births }\end{array}$ \\
\hline $\begin{array}{l}2000 \text { Eligibility } \\
2002 \text { Eligibility } \\
2004 \text { Eligibility } \\
2005 \text { Eligibility }\end{array}$ & $\begin{array}{c}0.048 \\
(0.015)\end{array}$ & $\begin{array}{c}0.033 \\
(0.016)\end{array}$ & $\begin{array}{c}0.004 \\
(0.017)\end{array}$ & $\begin{array}{l}-0.008 \\
(0.017)\end{array}$ & $\begin{array}{c}0.221 \\
(0.019)\end{array}$ & $\begin{array}{c}0.201 \\
(0.017)\end{array}$ & $\begin{array}{c}0.011 \\
(0.023)\end{array}$ & $\begin{array}{c}0.014 \\
(0.020)\end{array}$ \\
\hline
\end{tabular}

Robust standard errors in parentheses. 
Table 4: Percent Change in 2004 Turnout Resulting from 1988 - 1998Eligibility

\begin{tabular}{|c|c|c|c|c|c|c|}
\hline Population Control & $\begin{array}{c}(1) \\
\text { Fixed } \\
\text { Effects }\end{array}$ & $\begin{array}{c}(2) \\
\text { California } \\
\text { Births } \\
\end{array}$ & $\begin{array}{c}(3) \\
\text { Fixed } \\
\text { Effects }\end{array}$ & $\begin{array}{c}(4) \\
\text { California } \\
\text { Births } \\
\end{array}$ & $\begin{array}{c}(5) \\
\text { Fixed } \\
\text { Effects }\end{array}$ & $\begin{array}{c}(6) \\
\text { California } \\
\text { Births } \\
\end{array}$ \\
\hline $\begin{array}{l}1996 \text { Eligibility } \\
1992 \text { Eligibility } \\
1988 \text { Eligibility }\end{array}$ & $\begin{array}{c}0.014 \\
(0.012)\end{array}$ & $\begin{array}{c}0.026 \\
(0.013)\end{array}$ & $\begin{array}{c}0.033 \\
(0.013)\end{array}$ & $\begin{array}{c}0.002 \\
(0.014)\end{array}$ & $\begin{array}{c}-0.010 \\
(0.012) \\
\end{array}$ & $\begin{array}{c}0.005 \\
(0.014) \\
\end{array}$ \\
\hline Population Control & $\begin{array}{c}(7) \\
\text { Fixed } \\
\text { Effects }\end{array}$ & $\begin{array}{c}(8) \\
\text { California } \\
\text { Births } \\
\end{array}$ & $\begin{array}{c}\text { (9) } \\
\text { Fixed } \\
\text { Effects }\end{array}$ & $\begin{array}{c}(10) \\
\text { California } \\
\text { Births } \\
\end{array}$ & $\begin{array}{c}\text { (11) } \\
\text { Fixed } \\
\text { Effects }\end{array}$ & $\begin{array}{c}(12) \\
\text { California } \\
\text { Births } \\
\end{array}$ \\
\hline $\begin{array}{l}1998 \text { Eligibility } \\
1994 \text { Eligibility } \\
1990 \text { Eligibility }\end{array}$ & $\begin{array}{c}0.018 \\
(0.013)\end{array}$ & $\begin{array}{c}0.004 \\
(0.014)\end{array}$ & $\begin{array}{c}0.000 \\
(0.013)\end{array}$ & $\begin{array}{c}0.004 \\
(0.014)\end{array}$ & $\begin{array}{c}-0.002 \\
(0.014)\end{array}$ & $\begin{array}{c}-0.008 \\
(0.014)\end{array}$ \\
\hline
\end{tabular}

Robust standard errors in parentheses. 
Table 5: Percent Change in Party Affiliation of 2004 Participants Resulting from 1988 - 1998 Eligibility

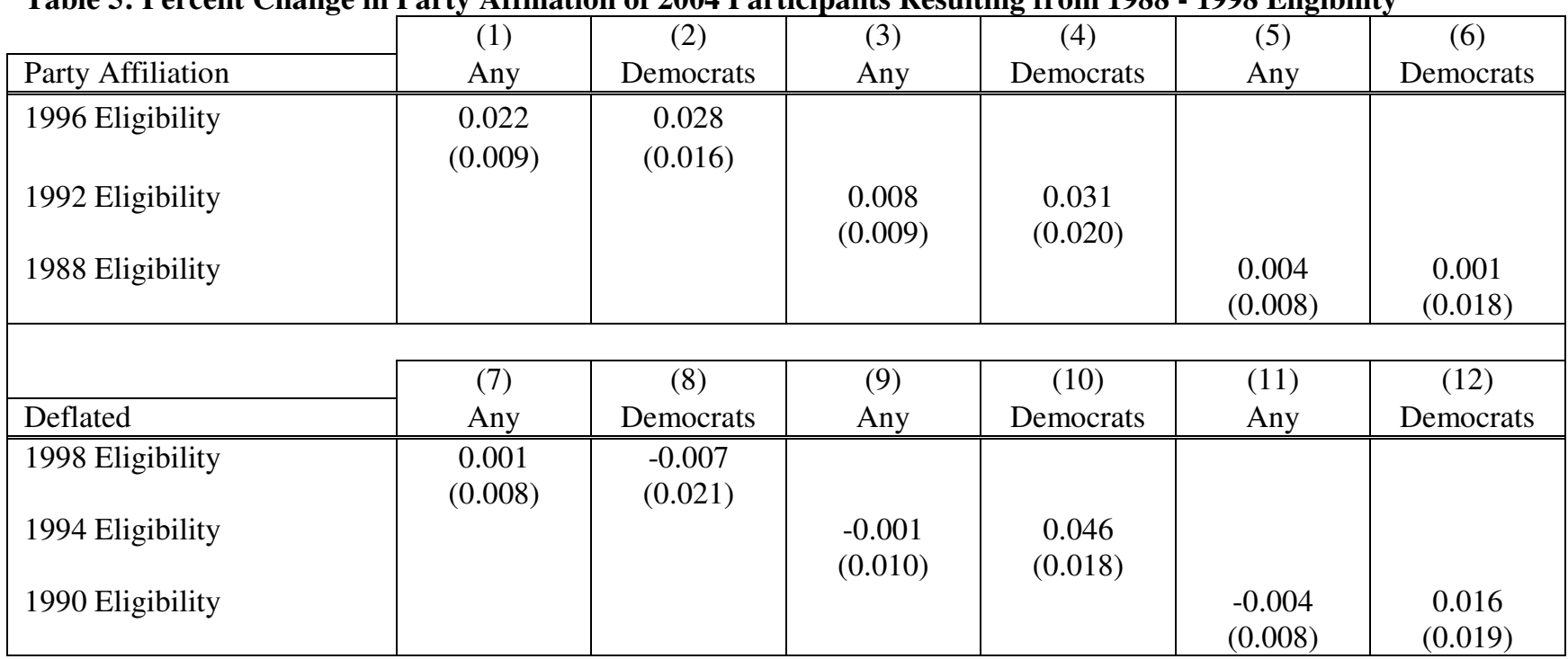

All coefficients estimated by replacing the dependent variable in Equation 7 with the percentage of 2004 participants born on day $d$ in year y affiliating with a given party. Sample restricted to participants registering after the 2000 election. Robust standard errors in parentheses. 